\title{
Comparison of laparoscopic-assisted vaginal hysterectomy, total abdominal hysterectomy and vaginal hysterectomy: A four years retrospective study in tertiary care centre
}

\author{
Namrata Vasant Padvi*, Jitendra Pundalik Ghumare
}

Department of Obstetrics and Gynecology, Shri Bhausaheb Hire Government Medical College, Dhule, Maharashtra, India

Received: 13 August 2018

Accepted: 18 August 2018

\section{*Correspondence:}

Dr. Namrata Vasant Padvi,

E-mail: nams25padvi@gmail.com

Copyright: () the author(s), publisher and licensee Medip Academy. This is an open-access article distributed under the terms of the Creative Commons Attribution Non-Commercial License, which permits unrestricted non-commercial use, distribution, and reproduction in any medium, provided the original work is properly cited.

\section{ABSTRACT}

Background: Hysterectomy is one of the commonest gynaecological operations performed in India. Traditional surgical treatments performed are abdominal hysterectomy and vaginal hysterectomy. Vaginal and laparoscopic procedures are considered "minimally invasive" surgical approaches because they do not require a large abdominal incision and, thus, typically are associated with shortened hospitalization and postoperative recovery times compared with open abdominal hysterectomy. With the aid of laparoscopic procedure, a potential abdominal hysterectomy can be converted to a vaginal one and a difficult vaginal hysterectomy can be converted into a fairly simple vaginal hysterectomy. Aim of the present study is to compare above methods of hysterectomy in terms of operating time, estimated blood loss, and postoperative hospital stay and complication, so as to provide best course of treatment to patient.

Methods: A retrospective observational study was conducted in tertiary care centre. Four-year data was collected from January 2012 to December 2016. Cases of LAVH with benign gynaecological condition and up to 12 weeks size uterus, without any associated medical condition were selected in study randomly, and compare with cases of NDVH, TAH in terms of duration of operative procedure, blood loss during surgery, and postoperative hospital stay.

Results: In present study we found that average duration of procedure in LAVH was 84.35 minute, which was maximum compare to other method. Estimated blood loss in LAVH was least as compare to NDVH and TAH it was maximum. The average hospital stays in LAVH and NDVH was less as compared to TAH.

Conclusions: LAVH should be considered a better approach in view of the relatively less blood loss and intraoperative complication. Due to lack of large randomized controlled trials, the role of Laparoscopic hysterectomy is difficult to define.

Keywords: Laparoscopic assisted vaginal hysterectomy (LAVH), Non-decent vaginal hysterectomy (NDVH), Total abdominal hysterectomy (TAH)

\section{INTRODUCTION}

Hysterectomy is the second most common operation performed by the Gynaecologists, next only to caesarean section and can be done through abdominal, vaginal and laparoscopic routes. ${ }^{1-3}$ Traditional abdominal and vaginal hysterectomies represent the most and least invasive techniques respectively. Abdominal hysterectomy is preferred over the vaginal route due to ease and convenience offered by a large abdominal incision. 
Laparoscopic route is associated with increased operating times and rise in the rate of intraoperative injuries. ${ }^{4}$ Despite this, LAVH is gaining popularity fast due to the obvious advantage of direct visualization of uterus and adenexa prior to any operative dissection.

Non-decent vaginal hysterectomy there is a definite hesitation amongst gynaecologists to perform it, the reasons include technical difficulty, inability to perform oophorectomy etc. It is considered that big size uterus, previous surgeries, associate adenexal pathology, pelvic inflammatory disease and endometriosis makes vaginal hysterectomy difficult to be performed and should not be considered as contradiction to non-decent vaginal hysterectomy. ${ }^{5}$ It can be performed in properly selected patients with the advantage of less operative and anaesthetic complications as compared to abdominal hysterectomy. 6,7

Selection of the route of hysterectomy can be influenced by various factors like the size and shape of the uterus, accessibility to the uterus, associated adenexal pathology, surgeon experience and available hospital facility. The gynaecologist should discuss the options with the patient and make clear decision on which route of hysterectomy to be performed so as to provide maximum benefits and minimize side effects in the specific clinical situation. In our centre, hysterectomy is performed by laparoscopic, abdominal and vaginal routes. The aim of this study was to evaluate the most efficient route of hysterectomy in women by comparing the intra and postoperative complications of vaginal and abdominal and laparoscopic hysterectomies. Outcome data of these procedures would be helpful for both clinicians and patients to consider best approach for hysterectomy in order to provide maximum benefits and satisfaction to the patient.

\section{METHODS}

A retrospective observational study was conducted in tertiary care centre Shri Bhausaheb Hire Government Medical College, Dhule. Four-year data was collected from January 2012 to December 2016 to find out better approach for hysterectomy by comparing safety and efficiency of different methods of hysterectomy. Cases of LAVH with benign gynaecological condition and up to 12 weeks size uterus, without any associated medical condition were selected in study randomly, and compare with cases of NDVH, TAH with similar gynaecological condition.

All cases were allotted in 3 groups and compared for their efficacy and safety in terms of Duration of operative procedure, Blood loss during surgery, Postoperative hospital stay. All these patients were admitted in gynaecology department after thorough examination and were subjected to routine preoperative investigations.

Patients who had multiple medical disorders or more than one previous caesarean section were excluded from the study. All the patients were assessed for the size and mobility of uterus. After all the preoperative work up the patients were either subjected to LAVH and NDVH, TAH. Patients undergoing NDVH and TAH were given either spinal or epidural anaesthesia, while LAVH done under general anaesthesia.

\section{RESULTS}

Total 350 cases were including in study, out of which 100 $(28.57 \%)$ were LAVH, $70(20 \%)$ were NDVH, and 180 $(51.42 \%)$ were TAH. All cases were of between the age of 35 to 60 years. In LAVH group maximum cases $62 \%$ were in 41-50 years of age group. In NDVH $57.14 \%$ and $67.22 \%$ in TAH were in $41-50$ years of age group (Table 1).

Table 1: Age distribution of cases between various procedures.

\begin{tabular}{|llll|}
$\begin{array}{l}\text { Age } \\
\text { group }\end{array}$ & $\begin{array}{l}\text { Number of } \\
\text { cases in } \\
\text { LA VH (100) }\end{array}$ & $\begin{array}{l}\text { Number of } \\
\text { cases in } \\
\text { NDVH }(70)\end{array}$ & $\begin{array}{l}\text { Number of } \\
\text { cases in } \\
\text { TAH }(180)\end{array}$ \\
\hline $\begin{array}{l}<30 \\
\text { years }\end{array}$ & 0 & 0 & 0 \\
\hline $\begin{array}{l}31-40 \\
\text { years }\end{array}$ & $37(37 \%)$ & $24(34.28 \%)$ & $57(31.11 \%)$ \\
$\begin{array}{l}41-50 \\
\text { years }\end{array}$ & $62(62 \%)$ & $40(57.14 \%)$ & $121(67.22 \%)$ \\
\hline $\begin{array}{l}51-60 \\
\text { years }\end{array}$ & $1(1 \%)$ & $6(8.57 \%)$ & $2(1.11 \%)$ \\
\hline $\begin{array}{l}>61 \\
\text { years }\end{array}$ & 0 & 0 & 0 \\
\hline
\end{tabular}

Mean age in all three group is between 40-45yrs (Table 2).

Table 2: Mean age of cases between various procedures.

\begin{tabular}{llll} 
& LAVH & NDVH & TAH \\
Mean age & $44.09 \pm 4.71$ & $44.48 \pm 4.89$ & $43.98 \pm 4.38$ \\
\hline
\end{tabular}

The duration of surgery in LAVH group in $68 \%$ of cases was between $81-90$ min. In NDVH group the duration of surgery in $31.42 \%$ of cases were between $71-80 \mathrm{~min}$.

Table 3: Distribution of cases according to duration of various procedures.

\begin{tabular}{|llll|}
$\begin{array}{l}\text { Duration } \\
\text { of } \\
\text { procedures }\end{array}$ & $\begin{array}{l}\text { Number } \\
\text { of cases in } \\
\text { LA VH }\end{array}$ & $\begin{array}{l}\text { Number of } \\
\text { cases in } \\
\text { NDVH }\end{array}$ & $\begin{array}{l}\text { Number } \\
\text { of cases in } \\
\text { TAH }\end{array}$ \\
\hline$<50 \mathrm{~min}$ & 0 & 0 & 0 \\
\hline $51-60 \mathrm{~min}$ & 0 & $20(28.57 \%)$ & $73(40.55 \%)$ \\
\hline $61-70 \mathrm{~min}$ & $3(3 \%)$ & $20(28.57 \%)$ & $37(20.55 \%)$ \\
\hline $71-80 \mathrm{~min}$ & $27(27 \%)$ & $22(31.42 \%)$ & $25(13.88 \%)$ \\
\hline $81-90 \mathrm{~min}$ & $68(68 \%)$ & $8(11.42 \%)$ & $43(23.88 \%)$ \\
\hline$>91 \mathrm{~min}$ & $2(2 \%)$ & 0 & $2(1.11 \%)$ \\
\hline
\end{tabular}


In TAH group the duration of surgery in $40.55 \%$ of cases were between 51-60 min (Table 3). The blood loss during surgery in $90 \%$ of LAVH cases were less than $30 \mathrm{ml}$. In NDVH group the blood loss during surgery in $54.28 \%$ of cases were less than $30 \mathrm{ml}$, and in $45.71 \%$ of cases it was between $30-50 \mathrm{ml}$. In TAH group the blood loss during surgery in all cases were more than $50 \mathrm{ml}$ (Table 4).

Table 4: Distribution of cases according to blood loss during of various procedures.

\begin{tabular}{|llll|}
\hline Blood loss & $\begin{array}{l}\text { Number } \\
\text { of cases } \\
\text { in LA VH }\end{array}$ & $\begin{array}{l}\text { Number of } \\
\text { cases in } \\
\text { NDVH }\end{array}$ & $\begin{array}{l}\text { Number of } \\
\text { cases in } \\
\text { TAH }\end{array}$ \\
\hline$<30 \mathrm{ml}$ & $90(90 \%)$ & $38(54.28 \%)$ & 0 \\
\hline $31-50 \mathrm{ml}$ & $10(10 \%)$ & $32(45.71 \%)$ & 0 \\
\hline $51-70 \mathrm{ml}$ & 0 & 0 & $90(50 \%)$ \\
\hline $71-90 \mathrm{ml}$ & 0 & 0 & $73(40.55 \%)$ \\
\hline$>91 \mathrm{ml}$ & 0 & 0 & $17(9.44 \%)$ \\
\hline
\end{tabular}

The duration of hospital stay after surgery in all cases of LAVH group was between 4-5 days. In NDVH group the duration of hospital stay after surgery in $91.42 \%$ of cases were between 5-7 days and $8.57 \%$ cases it was more than 7 days. In TAH group the duration of hospital stay after surgery in $80.55 \%$ of cases were between 5-7 days and $16.44 \%$ cases it was more than 7 days (Table 5).

Table 5: Distribution of cases according to hospital stay after various procedures.

\begin{tabular}{|llll|}
\hline $\begin{array}{l}\text { Hospital } \\
\text { stay }\end{array}$ & $\begin{array}{l}\text { Number } \\
\text { of cases in } \\
\text { LA VH }\end{array}$ & $\begin{array}{l}\text { Number of } \\
\text { cases in } \\
\text { NDVH }\end{array}$ & $\begin{array}{l}\text { Number of } \\
\text { cases in } \\
\text { TAH }\end{array}$ \\
\hline$<5$ days & 0 & 0 & 0 \\
\hline 5-7 days & $100(100 \%)$ & $64(91.42 \%)$ & $145(80.55 \%)$ \\
\hline$>7$ days & 0 & $6(8.57 \%)$ & $35(16.44 \%)$ \\
\hline
\end{tabular}

On comparison between LAVH and NDVH we observed that the mean duration of procedure in LAVH was 84.35 minute and NDVH was 69.85 minute with $p$ value of $<0.001$ which is significant. Average blood loss in LAVH was $25 \mathrm{ml}$ and in $\mathrm{NDVH}$ it was $35 \mathrm{ml}$, with $\mathrm{p}$ value of $<0.001$ which is significant. The hospital stay in LAVH was 5.4 days and NDVH was 5.5 days with $\mathrm{p}$ value of 0.083 which is not significant (Table 6).

Table 6: Comparison between different variables related to LAVH and NVDH.

\begin{tabular}{|llll|}
\hline & $\begin{array}{l}\text { Mean duration } \\
\text { of procedure }\end{array}$ & $\begin{array}{l}\text { Average } \\
\text { blood loss }\end{array}$ & $\begin{array}{l}\text { Mean } \\
\text { hospital } \\
\text { stay }\end{array}$ \\
\hline LAVH & $84.35 \pm 6.01$ & $25 \pm 6.74$ & $5.4 \pm 0.66$ \\
\hline NDVH & $69.85 \pm 9.12$ & $35.71 \pm 10.29$ & $5.57 \pm 0.94$ \\
\hline $\begin{array}{l}\text { Significance } \\
(t, p) \text { value }\end{array}$ & 12.19 & -8.19 & -1.34 \\
$(<0.001)$ & $(<0.001)$ & $(0.083)$ \\
\hline
\end{tabular}

*Variables are compared using student's t-test, showing t values with p-values shown in brackets
On comparison between LAVH and TAH we observed that the mean duration of procedure in LAVH was 84.35 minute and TAH was 70.55 minute with $p$ value of $<0.001$ which is significant. Average blood loss in LAVH was $25 \mathrm{ml}$ and in TAH it was $75.38 \mathrm{ml}$, with $\mathrm{p}$ value of $<0.001$ which is also significant.

The hospital stay in LAVH was 5.4 days and TAH was 6.4 days with $\mathrm{p}$ value of $<0.001$ which is significant (Table 7).

Table 7: Comparison between different variables related to LAVH and TAH.

\begin{tabular}{|llll|} 
& $\begin{array}{l}\text { Mean } \\
\text { duration of } \\
\text { procedure }\end{array}$ & $\begin{array}{l}\text { Average } \\
\text { blood loss }\end{array}$ & $\begin{array}{l}\text { Mean } \\
\text { hospital stay }\end{array}$ \\
\hline LAVH & $84.35 \pm 6.01$ & $25 \pm 6.74$ & $5.4 \pm 0.66$ \\
\hline TAH & $70.55 \pm 11.19$ & $75.38 \pm 11.88$ & $6.48 \pm 1.11$ \\
\hline $\begin{array}{l}\text { Significance } \\
(t, p) \text { value }\end{array}$ & 11.10 & -39.33 & -6.27 \\
$(<0.001)$ & $(<0.001)$ & $(<0.001)$ \\
\hline
\end{tabular}

*Variables are compared using student's t-test, showing $\mathrm{t}$ values with p-values shown in brackets

On comparison between TAH and NDVH we observed that the mean duration of procedure in NDVH was 69.85 minute and TAH was 70.55 minute with $p$ value of 0.233 which is not significant.

Average blood loss in NDVH was $35 \mathrm{ml}$ and in TAH it was $75.38 \mathrm{ml}$, with $\mathrm{p}$ value of $<0.001$ which is significant. The hospital stay in NDVH was 5.5 days and TAH was 6.4 days with $\mathrm{p}$ value of $<0.001$ which is also significant (Table 8).

Table 8: Comparison between different variables related to NDVH and TAH.

\begin{tabular}{|llll|}
\hline & $\begin{array}{l}\text { Mean } \\
\text { duration of } \\
\text { procedure }\end{array}$ & $\begin{array}{l}\text { Average } \\
\text { blood loss }\end{array}$ & $\begin{array}{l}\text { Mean } \\
\text { hospital } \\
\text { stay }\end{array}$ \\
\hline NDVH & $69.85 \pm 9.12$ & $35.71 \pm 10.29$ & $5.57 \pm 0.94$ \\
\hline TAH & $70.55 \pm 11.19$ & $75.38 \pm 11.88$ & $6.48 \pm 1.11$ \\
\hline $\begin{array}{l}\text { Significance } \\
(t, p) \text { value }\end{array}$ & -0.72 & -24.8 & -6.27 \\
\hline
\end{tabular}

*Variables are compared using student's t-test, showing t values with p-values shown in brackets

Authors also compared different complication associated with all above methods and we found that, among all $6 \%$ of cases required conversion to laparotomy in LAVH group and $1 \%$ in NDVH group due to some surgical difficulties. Postoperative pain was maximum in abdominal hysterectomy group that is $42.22 \%$ while least with NDVH group. Postoperative fever was also high $12.22 \%$ with abdominal hysterectomy cases. Postoperative blood transfusion required maximum $13.33 \%$ in TAH group. Among LAVH group $2 \%$ patient had bowel and bladder injury, while in TAH $6.11 \%$ cases suffer 
same fate. Wound infection was higher $10.5 \%$ with TAH group compared to rest (Table 9).

Table 9: Comparison between different complications related to LAVH, NDVH and TAH.

\begin{tabular}{|llll|}
\hline & $\begin{array}{l}\text { LA VH } \\
(\mathbf{1 0 0})\end{array}$ & $\begin{array}{l}\text { NDVH } \\
(\mathbf{7 5})\end{array}$ & $\begin{array}{l}\text { TAH } \\
(\mathbf{1 8 0})\end{array}$ \\
\hline $\begin{array}{l}\text { Conversion to } \\
\text { laparotomy }\end{array}$ & $6(6 \%)$ & $1(1.3 \%)$ & - \\
\hline Post op pain & $35(35 \%)$ & $14(18.66 \%)$ & $76(42.22 \%)$ \\
\hline $\begin{array}{l}\text { Post of fever } \\
\text { Blood }\end{array}$ & $7(7 \%)$ & $6(8 \%)$ & $22(12.22 \%)$ \\
transfusion & $2(2 \%)$ & $5(6.6)$ & $24(13.33 \%)$ \\
\hline $\begin{array}{l}\text { Bowel/ } \\
\text { bladder injury }\end{array}$ & $2(2 \%)$ & - & $11(6.11 \%)$ \\
\hline $\begin{array}{l}\text { Wound } \\
\text { infection }\end{array}$ & $2(2 \%)$ & - & $19(10.5 \%)$ \\
\hline $\begin{array}{l}\text { Hernia/ } \\
\text { dehiscence }\end{array}$ & $1(1 \%)$ & - & $2(1.11 \%)$ \\
\hline $\begin{array}{l}\text { Abdominal wall } \\
\text { hematoma }\end{array}$ & $2(2 \%)$ & - & $4(2.22 \%)$ \\
\hline
\end{tabular}

\section{DISCUSSION}

Hysterectomy is one of the commonest gynaecological operations performed in India. Although hysterectomy was initiated in initial years through vaginal route, the abdominal has become most travelled one. And with advent of better anaesthesia and newer trends in laparoscopy there has been gradual shift from traditional surgical techniques to laparoscopic procedures.

In our centre, hysterectomy is performed by laparoscopic, abdominal and vaginal routes. We performed a retrospective observational study. Four-year data was collected from January 2012 to December 2016 to compare different methods of hysterectomy. All cases were allotted in three groups and compared for their efficacy and safety in terms of Duration of operative procedure, Blood loss during surgery, Postoperative hospital stay.

In present study we found that average duration of procedure in LAVH is 84.35 minute, NDVH is 69.85 minute while in TAH is 70.55 minute. So maximum duration is required in LAVH group and it was least in NDVH group. Estimated blood loss in LAVH was $25 \mathrm{ml}$, in NDVH it was $35 \mathrm{ml}$ and TAH it was maximum that is $75.38 \mathrm{ml}$. The average hospital stay in LAVH is 5.4 days in NDVH was 5.5 days and it was 6.4 day in TAH. We also correlated present study with similar studies done in past which compare same variables. Our results were consistent with the results of following study.

A retrospective study of 602 hysterectomies was performed by Aniuliene $\mathrm{R}$ et al. Among all hysterectomies performed 51 [8.5\%] were laparoscopic, 203 [33.7\%] were vaginal, and 348 [57.8\%] were abdominal hysterectomies. The objective of his study was to evaluate and compare operative complications, blood loss, and hospital stay and postoperative results and differences among laparoscopic, vaginal, and abdominal hysterectomies performed. His results were similar to present study.

The most common procedure performed was abdominal hysterectomy. He observed minimum complication rate after laparoscopic and vaginal hysterectomies. Laparoscopic hysterectomy had minimum amount of blood loss. Abdominal hysterectomy patients required on average a longer hospital stay as compared to laparoscopic and vaginal hysterectomies. ${ }^{8}$ Ribeiro SC et al performed a randomized study. Total 60 cases were included. Abdominal hystrectomy $[n=20]$, vaginal hysterectomy $[\mathrm{n}=20]$, and laparoscopic hysterectomy $[n=20]$. The purpose of study was to evaluated operative time, blood loss and inflammatory response in patients with hysterectomy.

When compared with total abdominal and laparoscopic hysterectomy, vaginal hysterectomy proved to be superior in terms of operative time and inflammatory response and it should be the first option for hysterectomy. He concluded that Laparoscopic hysterectomy should be considered when the vaginal approach is unfeasible, showing clear advantages over abdominal hysterectomy. ${ }^{9}$ Ottosen $\mathrm{C}$ et al did a prospective randomized study. There were 40 cases in each group. The aim was to detect differences in clinical short-term outcome between laparoscopic assisted vaginal hysterectomy, total abdominal hysterectomy and vaginal hysterectomy.

Traditional vaginal hysterectomy proved to be feasible and the faster operative technique compared with laparoscopic assisted vaginal hysterectomy. Abdominal hysterectomy required longer hospital stay post operatively as compared with traditional vaginal hysterectomy. Study concluded that vaginal hysterectomy should be a primary method for uterine removal. ${ }^{10}$ In present study we also observe different complication related to above three procedure, we found few complications like postoperative pain, fever, need of blood transfusion and wound gape more in TAH group. No significant differences are found in intraoperative visceral injuries. In comparison to other studies we found few similar results.

In a meta-analysis of RCT's, no significant differences in urinary tract injury for laparoscopic versus vaginal hysterectomy. No other intraoperative visceral injuries (including bladder and ureter considered independently, and bowel and vascular injury) showed a significant difference between surgical approaches. ${ }^{11}$ While complication rate was statistically lower in the $\mathrm{VH}$ group [p<.05] compared to LAVH group in a study done by Darai et al and Monte David-Montefiore et al. ${ }^{12}$ In present study we found that average duration of procedure in $\mathrm{LAVH}$ is longer as compare to other, and 
blood loss and post op stay was minimum as compare to other making it superior to other. Complication rate were also not that significant. The biggest drawback of laparoscopic route over vaginal one is its cost due to expensive disposable instruments, prolonged operating and anaesthesia time and the need for a trained senior gynaecologist.

As far as abdominal route is considered, estimated blood loss and post op complication were maximum with this. Although this approach to hysterectomy ensures good haemostasis under direct vision, while during the vaginal operation the vault is closed and subsequent bleeding from the vagina between the mucosa and the peritoneum can give rise to problems, laparoscopic approach can help check haemostasis and reduce the incidence of vault hematomas. However, this aspect needs to be evaluated in further studies. In present study no outcomes are significantly worse for vaginal hysterectomy compared to LAVH. Lack of uterine descent and nulliparity, fibroid uterus, need for oophorectomy, previous pelvic surgery should not be considered as contraindications to the vaginal route. With adequate vaginal access and technical skill, and good uterine mobility, vaginal hysterectomy can easily be performed.

There are clinical situations where vaginal surgeries are not appropriate such as dense pelvic adhesions; laparoscopically assisted vaginal hysterectomy can be useful adjunct to transvaginal hysterectomy and sometimes for certain concomitant adenexal surgery. Lack of training in vaginal surgery should not be considered as contraindication for vaginal hysterectomy. The learning curve of vaginal surgery is very short compared to laparoscopic surgery, however, the current scenario in residency programmes is not providing a level of surgical competency in performing difficult vaginal hysterectomies and there is a need to improve this training. LAVH should be considered a better approach in view of the relatively less blood loss and intraoperative complication, whereas transvaginal hysterectomy is preferable, not only for shorter operative time and minimal complications, but also for much lower costs. The role of Laparoscopic hysterectomy is difficult to define due to lack of large randomized controlled trials, therefore larger randomized controlled trials are required to compare different types of hysterectomies. It is quite clear that it cannot replace vaginal hysterectomy but may aid vaginal route in selected cases discussed above.

Funding: No funding sources Conflict of interest: None declared

Ethical approval: The study was approved by the Institutional Ethics Committee

\section{REFERENCES}

1. Bernstein SJ, McGlynn EA, Siu AL, Roth CP, Sherwood MJ, Keesey JW. The appropriateness of hysterectomy. A comparison of care in seven health plans. Health Maintenance Organization Quality of Care Consortium. JAMA. 1993;269(18):2398-402.

2. Grave EJ, Gillum BS. 1994 Summary. National hospital discharge survey. Advance data from vital and health statistics No 278. National Center for Health Statistics, Hyattsville, Maryland 1996.

3. West S, Drannov P. The hysterectomy Hoax. New York: Doubleday. 1994;214.

4. Richardson RE, Bournas N, Magos AL. Is laparoscopic hysterectomy a waste of time?. Obstet and Gynecol Sur. 1995;50(8):590-1.

5. Coulam CB, Pratt JH. Vaginal hysterectomy: is previous pelvic operation a contraindication. Am J Obstet Gynecol. 1973;116(2):252.

6. Pitkin RM. Vaginal hysterectomy in obese women. Obstet Gynecol. 1977;49(5):567-9.

7. Pratt JH, Daikoku NH. Obesity and vaginal hysterectomy. J Reprod Med. 1990;35(10):945-9.

8. Aniuliene R, Varzgaliene L, Varzgalis M. A comparative analysis of hysterectomies. Medicina. 2007;43(2):118-24.

9. Ribeiro SC, Ribeiro RM, Santos NC, Pinotti JA. A randomized study of total abdominal, vaginal and laparoscopic hysterectomy. Int J Gynaecol Obstet. 2003;83(1):37-43.

10. Consultant CO, Lingman G, Ottosen L. Three methods for hysterectomy: a randomised, prospective study of short term outcome. BJOG: An Int J Obstet Gynaecol. 2000 Nov;107(11):1380-5.

11. Johnson N, Barlow D, Lethaby A, Tavender E, Curr L, Garry R. Methods of hysterectomy: systematic review and meta analysis of randomized controlled trials. BMJ. 2005;330(7506):1478.

12. David-Montefiore E, Rouzier R, Chapron C, Darai E, Collegiale d'Obstétrique et Gynécologie de Paris-Ile de France. Surgical routes and complications of hysterectomy for benign disorders: a prospective observational study in French university hospitals. Human Repro. 2007;22(1):260-5.

Cite this article as: Padvi NV, Ghumare JP, Comparison of laparoscopic-assisted vaginal hysterectomy, total abdominal hysterectomy and vaginal hysterectomy: A four years retrospective study in tertiary care centre. Int J Reprod Contracept Obstet Gynecol 2018;7:3596-600. 